\title{
Erratum to: Longitudinal associations between conduct problems and depressive symptoms among girls and boys with early conduct problems
}

\author{
Martine Poirier $^{1} \cdot$ Michèle Déry $^{2} \cdot$ Caroline E. Temcheff $^{2} \cdot$ Jean Toupin $^{2} \cdot$ \\ Pierrette Verlaan $^{2} \cdot$ Jean-Pascal Lemelin $^{2}$
}

Published online: 9 December 2015

(C) Springer-Verlag Berlin Heidelberg 2015

\section{Erratum to: Eur Child Adolesc Psychiatry DOI 10.1007/s00787-015-0796-z}

The support by the Canadian Institutes of Health Research, the Social Sciences and Humanities Research Council of Canada and the Fonds de recherche du Québec-Société et Culture was erroneously not mentioned in the published version of the Longitudinal associations between conduct problems and depressive symptoms among girls and boys with early conduct problems. The authors therefore would like to add the following acknowledgement.

\section{Acknowledgments}

This study was funded by the Canadian Institutes of Health Research (NRF 82694) and the Social Sciences and Humanities Research Council of Canada (SSHRC 37890). Support for this research was also provided by the Fonds de recherche du Québec-Société et Culture by means of a postdoctoral fellowship to the first author. We thank the children, parents, and teachers who participated in the study.

The authors apologize for the mistake.

The online version of the original article can be found under doi:10.1007/s00787-015-0796-z.

Martine Poirier

martine_poirier@uqar.ca

Michèle Déry

michele.dery@usherbrooke.ca

Caroline E. Temcheff

caroline.temcheff@usherbrooke.ca

Jean Toupin

jean.toupin@usherbrooke.ca

Pierrette Verlaan

pierrette.verlaan@usherbrooke.ca

Jean-Pascal Lemelin

jean-pascal.lemelin@usherbrooke.ca

1 Department of Education, Université du Québec à Rimouski, 300, allée des Ursulines, C. P. 3300, succ. A, Rimouski, QC G5L 3A1, Canada

2 Department of Psychoeducation, Université de Sherbrooke, Sherbrooke, Canada 